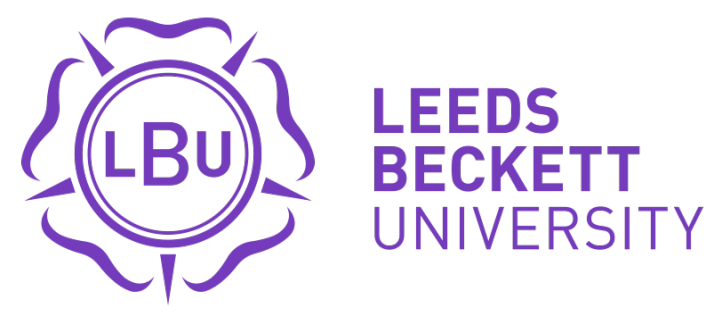

Citation:

Rodrigues, S and Sinval, J and Queirós, C and Marôco, J and Kaiseler, M (2019) Transitioning from recruit to officer : An investigation of how stress appraisal, and coping influence engagement. International Journal of Selection and Assessment, 27 (2). pp. 152-168. ISSN 0965-075X DOI: https://doi.org/10.1111/ijsa.12238

Link to Leeds Beckett Repository record:

https://eprints.leedsbeckett.ac.uk/id/eprint/5807/

Document Version:

Article (Accepted Version)

The aim of the Leeds Beckett Repository is to provide open access to our research, as required by funder policies and permitted by publishers and copyright law.

The Leeds Beckett repository holds a wide range of publications, each of which has been checked for copyright and the relevant embargo period has been applied by the Research Services team.

We operate on a standard take-down policy. If you are the author or publisher of an output and you would like it removed from the repository, please contact us and we will investigate on a case-by-case basis.

Each thesis in the repository has been cleared where necessary by the author for third party copyright. If you would like a thesis to be removed from the repository or believe there is an issue with copyright, please contact us on openaccess@leedsbeckett.ac.uk and we will investigate on a case-by-case basis. 
Transitioning from recruit to officer: An investigation of how stress appraisal, and coping influence engagement.

Susana Rodrigues $^{1 *}$, Jorge Sinval ${ }^{2,3^{*}}$, Cristina Queirós ${ }^{4}$, João Marôco ${ }^{3}$, and Mariana Kaiseler $^{5}$,

${ }^{1}$ Institute for Systems Engineering and Computers - Technology and Science (INESC TEC), Porto, Portugal.

${ }^{2}$ Instituto Universitário de Lisboa (ISCTE-IUL), Business Research Unit (BRU-IUL), Lisbon, Portugal.

${ }^{3}$ William James Center for Research, ISPA - Instituto Universitário, Lisbon, Portugal.

${ }^{4}$ Faculty of Psychology and Education Sciences, University of Porto, Portugal. ${ }^{5}$ Institute for Sport, Physical Activity and Leisure, Leeds Beckett University, UK. Author Note:

Correspondence should be sent to: Susana Rodrigues. INESC TEC - Rua Dr. Roberto Frias s/n Edifício 1, 4200-465 Porto Portugal. Telephone number: 222094000 Email: scpr@inescporto.pt

Acknowledgements: This work was supported by the European Union Seventh Framework Programme ([FP7/2007-2013] [FP7/2007-2011]) under grant agreement ${ }^{\circ}$ [PCIG10-GA-2011-303880] and from Fundação para a Ciência e Tecnologia (FCT), Portugal (DFRH/BI/51845/2012). This work was produced with the support of INCD funded by FCT and FEDER under the project 22153-01/SAICT/2016. We would like to thank the Portuguese National Police Force (Polícia de Segurança Pública) and the Police Academy for the collaboration provided in this study. 


\title{
Transitioning from recruit to officer: An investigation of how stress appraisal, and coping influence engagement.
}

\begin{abstract}
This study investigated stress, coping and engagement among Portuguese officers while undergoing academy training and then one year later, when on duty. It was hypothesized that stress appraisal and coping preferences predicted engagement. Additionally, in order to test a full cross-lagged prediction model, it was hypothesized that stress, coping and engagement in recruits predicted these variables later when working as police officers. Structural Equation Modeling was used to test the research hypotheses. Results suggest that coping and stress appraisals do not seem to be strong predictors of work engagement among recruits and police officers on duty. With the exception of self-blame, that seems to be a strong predictor of work engagement among police officers on duty. These results highlight the need to investigate other potential variables such as working conditions that may better explain work engagement. Considering the positive influence of engagement on health, wellbeing and performance of police recruits and officers, future applied and theoretical implications are discussed.
\end{abstract}

Keywords: stress appraisal, coping, engagement, police officers 
According to the transactional perspective from Lazarus and Folkman (1984), stress occurs when demands exceed the person's adaptive resources. No event is considered inherently stressful, although it depends on the individual's subjective perception (Zakowski, Hall, Klein, \& Baum, 2001). Considering that stress is an inevitable aspect in everyday life, coping makes the difference in adaptational processes, being characterized by people's efforts to manage the external and/or internal demands of a situation (Lazarus \& Folkman, 1984). Evidence suggests that police work is a particularly stressful occupation even when undergoing academy training (Chappell \& Lanza-Kaduce, 2010; Strahler \& Ziegert, 2015) therefore it seems important to understand how this population copes with stress early in their career while transitioning from academy training to working on duty as officers. Accordingly, further attention should be dedicated to this area of study in order to provide stronger training interventions for officers on duty. Although previous research in the area of occupational health has provided strong insights, some methodological and conceptual limitations restrict conclusions (Hickman, Fricas, Strom, \& Pope, 2011). As an example a study by Kaiseler et al. (2014) investigating the influence of stress and coping on work engagement provided an important insight to this area of study, however conclusions may be limited by the cross-sectional nature of the research and the statistical analysis used. Moreover, previous research investigating police officers' occupational stress are mainly focused in describing the nature of stressors, without considering the appraisal process or potential impact on wellbeing (McCarty \& Lawrence, 2016). Additionally, most of police occupational health research has mainly focused in the relationship between psychological distress and coping, restricting conclusions on the understanding of wellbeing and optimal functioning.

Over the last two decades, growing evidence supports the study of engagement as an outcome variable for employee wellbeing (Ouweneel, Le Blanc, Schaufeli, \& van Wijhe, 2012). Engaged workers are energetic, dedicated, proactive and committed to high quality standards (Bakker \& Leiter, 2010). Following this argument, and considering that coping strategies seem to predict engagement among separate time points in an officer career, namely recruits (e.g., Kaiseler et al.,2014) and officers (e.g., Rothmann, Jorgensen, \& Hill, 2011), it seems crucial to understand the relationship between these 
variables during the transition from recruits to officers. To pursue this line of investigation the present study aims to investigate the relationship between stress appraisal, coping and engagement across two important phases of a police officer career, respectively while undergoing academy training, and one year later while working on duty.

\section{Literature Review}

\section{Stress and coping process}

In order to explain how people, cope with stress, Lazarus and Folkman (1984) proposed the transactional model of stress and coping. This model has been extensively used, and its theoretical foundations are well accepted by the academic community and practitioners (e.g.,Sakakibara \& Endo, 2016; Young, Partington, Wetherell, Gibson, \& Partington, 2014). According to this perspective stress and coping is a dynamic and recursive process that includes interactions between the environment, individual appraisal and efforts to cope with the implications originated by these events. Accordingly, an event may be perceived as stressful, when the demands of a situation exceed the resources of the individual to deal with that situation. The key variable in this model is appraisal. Stress appraisal encompasses two types of appraisals. First, the primary appraisal is related with the meaning that an individual gives to an event. When an event is appraised as being a threat to the individual's wellbeing, the secondary appraisal process begins. Secondary appraisal refers to a complex evaluative process, whereas the individual assesses the available coping options in relation to the specific situation (Lazarus \& Folkman, 1984). The secondary appraisal process addresses judgments of the resources available to the individual, such as coping strategies and the degree of perceived control in meeting the demands of the situation (Zakowski et al., 2001). Perceived control in this way influences the level of perceived stress as well as coping strategies. As an example, higher perceptions of control are associated with positive appraisals (Lazarus and Folkman, 1984). When people face stressful situations, coping strategies are used in order to deal with the events. Lazarus and Folkman (1984) defined coping as a "constantly changing cognitive and behavioral efforts to manage specific external and/or internal demands that are appraised as 
taxing or exceeding the resources of the person" (p.141). According to the same authors, coping responses can be classified into two higher order categories or dimensions: problem-focused (PF) and emotionfocused (EF). PF involves ones' efforts to deal with the situation, (e.g., problem solving, planning) whereas EF involves efforts to regulate the emotional distress associated with the situation (e.g., acceptance, seeking social support).

\section{Stress and coping among police personnel}

Policing is an example of a highly stressful occupation (Strahler \& Ziegert, 2015). Police organizations are institutions opened $24 \mathrm{~h}$ per day that need to be ready to respond effectively to a variety of societal demands. Police officers are likely to experience a vast array of stressors within a shift. For instance, an officer may be solving a confrontation with an offender, and simultaneously be called upon to help a family of a road-trauma victim (Williams, Ciarrochi, \& Deane, 2010). Some of these situations are stressful, frustrating, intense, and/or emotionally challenging, depending on the way officers' process and give meaning to their experiences (Colwell, Lyons, Bruce, Garner, \& Miller, 2011). Considering that the majority of studies analyzing police stress are focused on stressors typology rather than the way officers' appraised events, there seems to be a clear need to understand police officers' subjective experience of events (Colwell et al., 2011).

Before becoming a qualified police officer, individuals undertake a demanding period of training in the academy, preparing them to real world settings (Chappell \& Lanza-Kaduce, 2010) this. Academy training programs for officers are extremely demanding and include physical training, performing under stress, use of defensive tactics, weapons, and force. In what concerns to coping among police recruits, a longitudinal study conducted by McCarty and Lawrence (2016) among 227 American police recruits, concluded that coping shifted significantly over time, particularly recruits used more task-oriented and outreach strategies at the beginning of the academy and more avoidance coping strategies at the end. However, a limitation found was that although the paper suggested being informed by Lazarus and Folkman theoretical framework, stress appraisal was not assessed. Thus, restricting conclusions on whether the distinct coping strategies found were due to differences in appraisal. Accordingly, control 
appraisals may be related with more active and PF coping use, whereas lack of control appraisal may be associated with more use of EF coping (Folkman \& Moskowitz, 2004).

In regards to coping among officers, acknowledging that stress is inevitable in the profession, the understanding of how officers deal with it (i.e. coping) seems to be a research priority. Particularly considering the existing evidence suggesting that police personnel have limited coping abilities (Anshel, Umscheid, \& Brinthaupt, 2013). Despite this need, the evidence on ways of coping used by officers and their respective effectiveness are ambiguous and sometimes contradictory. As an example, Stepka and Basinska (2014) developed a study with 61 Polish police officers and found direct action and positive thinking were the most often used coping strategies. In contrast a study by Alexander and Walker (1994) aiming to investigate coping among 758 Scottish officers, found that officers typically used coping strategies such as talk with colleagues, work more and keep things to themselves. Hence, further research is warranted investigating coping and among police force in order to inform effective stress management interventions for this population.

\section{Work engagement}

Acknowledging the insightful influence of positive psychology in occupational health research, the focus has now changed from a negative and distressful perspective to positive functioning and wellbeing (e.g., Rothmann et al., 2011). Engagement is a positive, fulfilling, work-related state of mind, characterized by vigor, dedication and absorption (Schaufeli, Salanova, González-Romá, \& Bakker, 2002). Vigor is characterized by high levels of energy and mental resilience at work. Dedication is defined as being strongly involved in work tasks and experiencing a sense of significance, enthusiasm, and challenge. Absorption is characterized by being fully concentrated and immersed in one's work, feeling that time flies while working (Schaufeli \& Bakker, 2004). Essentially, engaged workers perceive their work as stimulating, therefore they dedicate more time and effort (vigor), as an important and meaningful achievement (dedication), and as something that requires their full focus (absorption) (Bakker, Schaufeli, Leiter, \& Taris, 2008). There seems to be a clear relationship between stress and 
engagement, particularly engaged workers are more motivated and less likely to experience stressed. Accordingly, Schiffrin and Nelson (2009) suggested that by reducing stress levels, work engagement should increase.

Evidence suggests that work engagement is a relatively stable phenomenon, and not a momentary state of mind (e.g., Rothmann et al., 2011; Schaufeli, Bakker, \& Salanova, 2006). It seems to be a more persistent and pervasive affective cognitive state.However, this view is not unanimous and a contrast perspective suggests that engagement fluctuates over short periods of time (e.g., Sonnentag, Dormann, \& Demerouti, 2010), and following this trend the concept has been studied also at a daily level (e.g., Ouweneel et al., 2012). Thus, longitudinal research is required to understand the variance of the concept over time.

\section{Work engagement among police personnel}

Most empirical research up to date in the area of occupational health among police officers had mainly focused on negative concepts of health (e.g., stress, burnout). Following the positive psychology paradigm promoting the study of optimal functioning, as opposed to dysfunctions and problems (Seligman \& Csikszentmihalyi, 2000), research in policing occupational health should further understand officers' ${ }^{\prime}$ wellbeing in order to inform effective solutions.

Engagement seems to be predicted by a combination of job and personal resources (Bakker, Albrecht, \& Leiter, 2011). As an example, a study conducted by Rothmann et al. (2011) aiming to investigate the relationship between coping and work engagement among different professions, used a sample of 2,145 police officers. Findings suggest that personal resources, and particularly coping was the strongest predictor of work engagement. However, a limitation found in this study was that stress appraisal was not assessed.

A study conducted by Breevaart et al., 2015 with 847 Dutch police officers aiming to examine the process through which leader-member exchange (LMX) is related to followers' job performance. Results showed that employees in high-quality LMX relationships work in a more resourceful work environment (i.e. report more developmental opportunities and social support, but not more autonomy), facilitating 
work engagement and job performance. Other study conducted by Kaiseler et al. (2014) with a sample of 387 police recruits aimed to investigate the influence of stress appraisal (e.g.,stress intensity and control) and coping on work engagement. Results showed that perceived control over a stressor was associated with engagement and police recruits with higher levels of engagement, also used more active coping and less behavioral disengagement. Although this study made an important contribution to knowledge, it presented some shortcomings, related with the cross-sectional nature and the use of hierarchical regression analysis (HRA). The ability to deal with latent factors and measurement error reduction makes Structural Equation Modeling (SEM) more suitable than HRA (Marôco, 2014).

Considering that work engagement is an important predictor of wellbeing among recruits and officers, it seems important to understand if engagement tends to be maintained or whether it fluctuates over time. This insight would be useful to inform future engagement interventions targeting police recruits and officers.

\section{The current study}

Considering the importance of studying stress, coping and engagement among police professionals and acknowledging the previous research limitations, the current study aims to investigate the relationship between stress appraisal, coping and engagement among Portuguese police personnel transitioning from recruits to officers. Following the findings from Kaiseler et al. (2014) we intend to understand if, and how stress appraisal and coping are related with engagement in two important moments of an officer career. Considering the effectiveness of Lazarus and Folkman integrative model in analyzing the meaning, appraisal and coping process, this theoretical framework will inform our study. SEM will be used, considering that this powerful statistical technique will allow to assess the reliability and validity of the theoretical model. Hence, three hypotheses were developed:

H1: Stress appraisal and coping predicts work engagement among police recruits.

H2: Stress appraisal and coping predicts work engagement among police officers.

H3: Stress, coping and engagement among recruits predict stress, coping and engagement among police officers. 


\section{Method}

\section{Participants and procedure}

From a total of 387 Portuguese volunteers recruited as participants in wave 1 - while undergoing academy, 356 officers accepted to participate in wave 2 of the study -while working on duty (324 men, 32 women $)$. The recruits' ages ranged between 20 and 33 years $(M=24.1, S D=2.5)$ on wave 1 and from 21 to 34 years $(M=25.3, S D=2.4)$ on wave 2. Regarding participants' educational level, they had at least the secondary school grade, which is the national requirement to complete the proposed academy training. The study was approved by the University ethical department as well as Police Academy and National Direction of national police force (Políca de Segurança Pública - PSP). After granting ethics approval, the researchers sent digital letters to academy police recruits by e-mail, providing specific information about the study. Data was collected at two different moments in time over a twelve months period. In the first moment participants were police recruits enrolled in the Police Academy, undergoing their last month of training. In the second moment, participants were already police officers working on their first year of duty for the national police force in the city of Lisbon. The participants started by completing a consent form, and an online survey available on the academy Moodle platform (wave 1). Following twelve months, participants were contacted by email and asked to complete the second online survey (wave 2).

\section{Measures}

To assess stress and stress appraisal, participants were asked to remember a particular stressor related with academy training at wave 1 and with the profession at wave 2. Following this, participants were asked to report their primary appraisal of that stressor in terms of stress intensity, and secondary appraisal relating to control over the stressor. For both appraisal measures, responses were recorded on a Likert scale with response anchors 1 - "Not at all stressful" and 5 - "Extremely stressful", or 1- "No control at all" and 5 - "Full control". This approach was similar to that used in previous research in the area of stress appraisal and coping among police personnel (e.g., Kaiseler et al., 2014). 
Coping was assessed using BriefCOPE (Carver, 1997; Portuguese version: Pais-Ribeiro \& Rodrigues, 2004). The same questionnaire was completed twice in wave 1 and 2 (BriefCOPE). The BriefCOPE comprises 28 questions on a 4-point Likert scale (1 - "I haven't been doing this at all" to 4 "I've been doing this a lot"), where two items each form the following 14 sub-scales: Active Coping (AC); Planning (P); Positive Reframing (PR); Acceptance (A); Humour (H); Religion (R); Emotional Support (ES); Instrumental Support (IS); Self-Distraction (SD); Denial (D); Venting (V); Substance Use; Behavioural Disengagement (BD) and Self-Blame (SB).

Engagement was assessed using the 9-item Utrecht Work Engagement Scale (UWES-9; Schaufeli \& Bakker, 2009; Portuguese version: Picado, Marques Pinto, \& Lopes da Silva, 2008) with two versions: one for students (UWES-S-9), that was administrated for police recruits (wave 1) and one for workers (UWES-9), that was used for police officers (wave 2). This self-report scale was scored on a 7-point Likert scale (0 - "Never" to 6 - "Always"). The scale includes three subscales (Vigour; Dedication; Absorption) with three items each.

\section{Data Analysis}

All statistical analyses were performed with $R$ (R Core Team, 2018) and through the integrated development environment RStudio (RStudio Team, 2018). Preliminary analyses were conducted to explore the data. The missing values were imputed with the predicted values obtained through linear regression. In order to analyze items' distributional properties, the descriptive statistics were produced using the skimr package (McNamara, Arino de la Rubia, Zhu, Ellis, \& Quinn, 2018) to produce items' histograms, means, medians, minimum, maximum and standard deviation, the package plotrix (Lemon, 2006) to produce the standard error of the mean (SEM). The coefficient of variation (CV) was estimated with the package sjstats (Lüdecke, 2019), and the skewness (sk) and kurtosis (ku) were calculated with package psych (Revelle, 2018). Severe violations to univariate normality were considered for values of sk greater or equal to 3, and for ku values greater or equal to 7 (Finney, \& DiStefano, 2013).

The dimensionality of the instruments was tested using a set of confirmatory factor analysis (CFA) using the package lavaan (Rosseel, 2012). Four CFAs were conducted, respectively for the 
BriefCOPE at wave 1 and wave 2, and for the UWES-S-9, and UWES-9. The goodness-of-fit indices used were: $\chi^{2} / \mathrm{df}$ (ratio of chi-square to its degrees of freedom), SRMR (Standardized Root Mean Square Residual), TLI (Tucker Lewis Index), NFI (Normed Fit Index), RMSEA (root mean square error of approximation), and the CFI (Comparative Fit Index). The fit of the model was considered good for TLI, CFI and TLI values above 0.95; SRMR below 0.08 , and RMSEA values below 0.08 , and $\chi^{2} / \mathrm{df}$ smaller than 5 (Boomsma, 2000; Byrne, 2010; Hoyle, 1995; McDonald and Ho, 2002). The convergent validity was assessed with the average variance extracted (AVE; Fornell, \& Larcker, 1981). Values greater or equal to .50 were indicative of acceptable convergent validity (Hair, Black, Babin, \& Anderson, 2009).

The reliability of the scores in terms of internal consistency was calculated for each of the dimension of the psychometric instruments used. The ordinal omega ( $\omega$; Bollen, 1980; Raykov, 2001) was calculated; in addition the second-order factor reliability through the omega coefficient was assessed with three different estimators (Jorgensen, Pornprasertmanit, Schoemann, \& Rosseel, 2018). The $\omega_{L 2}$ (i.e., proportion of the second-order factor explaining the variance of the first-order factor level); the $\omega_{\text {partial Ll }}$ (i.e., proportion of observed variance explained by the second-order factor after controlling for the uniqueness of the first-order factor), and the $\omega_{L l}$ (i.e., proportion of the second-order factor explaining the total score). The reliability estimates were calculated with the semTools package (Jorgensen et al., 2018).

To test the causal models (H1, H2, and H3) a two-step approach was conducted according to the procedures described in Marôco (2014). The Weighted Least Squares Means and Variances (WLSMV) estimation method was used (Muthén, 1983) for the CFAs, H1, and H2. For H3 due to the number of parameters to be estimated, and since WLSMV performance with small samples is affected (Marôco, 2014), the Maximum Likelihood estimation with Robust (Huber-White) standard errors (MLR) estimator was used (Finney, DiStefano, \& Kopp, 2016). The causal trajectories were provided with $95 \%$ confidence intervals.

\section{Results}




\section{Measurement Model}

Items' distributional properties. Table 1 presents items' descriptive statistics for all items used in the structural models. For UWES-S-9 no items presented sk or ku values indicative of severe violations to normality. Items $1,5,8,9$, and 14 did not presented answers in all points of the Likert scale. UWES-9 did not present values of sk or ku indicative of severe normality violations. All items had answers in all Liker-scale points. The BriefCOPE data in the wave 1 presented two items (i.e., item 18 and item 25) with values of sk and ku indicative of severe normality violations, thus those items, and consequently their correspondent factors were removed from the CFA. All items presented answers in all Likert points. At wave 2, two items of the Brief-COPE presented sk and ku values indicative of severe normality violations (item 4 and item 11). Thus, those two items were removed, and consequently, the correspondent factor was removed from the CFA. Items 11, 4 and 16 were the only items that did not present answers for all point of Likert-scale. Regarding stress appraisal items, acceptable sk and ku values were found for waves 1 and 2, and answers were included in all points of the used Likert-scale.

Table 1

Dimensionality. The UWES-S-9 with a second-order latent factor had an excellent fit to the data $\left(\chi^{2}(27)=25.218, p=.562, N=360, \chi^{2} / d f=0.934, N F I=.992, C F I=1.000, T L I=\right.$ 1.000$, SRMR $=.049$, RMSEA $<.001, P($ rmsea $\leq .05)=.994,90 \%$ CI $] .000 ; .034[)$. The convergent validity evidence was satisfactory for all factors $\left(A V E_{V i g o r}=.66 ; A V E_{\text {Dedication }}=.68\right.$; $\left.A V E_{\text {Absorption }}=.76\right)$.

For the UWES-9 a second-order latent factor was also proposed with a residuals' correlation among item 1 and item 4 errors. This model presented a good fit to the data $\left(\chi^{2}(23)=\right.$ 59.572, $p<.001, N=360, \chi^{2} / d f=2.590, N F I=.998, C F I=.999, T L I=.998, S R M R=.033$, $R M S E A=.067, P($ rmsea $\leq .05)=.089,90 \% \mathrm{CI}] .046 ; .088[)$. In terms of convergent validity 
evidence, this was satisfactory for all factors $\left(A V E_{\text {Vigor }}=.70 ; A V E_{\text {Dedication }}=.83 ; A V E_{\text {Absorption }}\right.$ $=.55)$.

Regarding the BriefCOPE at wave 1, and since each factor has two items, the loadings for each pair of items in each factor were constrained to be equal. The CFA for the reduced model (with 12 of the 14 original dimensions of BriefCOPE) showed an unacceptable fit to the data $\left(\chi^{2}(273)=3,965.918, p<.001, N=360, \chi^{2} / d f=14.527, N F I=.862, C F I=.870, T L I\right.$ $=.820, S R M R=.182, R M S E A=.194, P(r m s e a \leq .05)<.001,90 \%$ CI ].189; .199[). Several pairs of items presented loadings below .50, such pairs of items were removed, and a reduced version with eight dimensions was obtained. This version presented acceptable fit to the data $\left(\chi^{2}(88)=\right.$ 413.856, $p<.001, N=360, \chi^{2} / d f=4.703, N F I=.957, C F I=.966, T L I=.953, S R M R=.079$, RMSEA $=.102, P($ rmsea $\leq .05)<.001,90 \%$ CI ].092; .112[). The convergent validity evidence was satisfactory $\left(A V E_{A C}=.86 ; A V E_{E S}=.46 ; A V E_{R}=.60 ; A V E_{P R}=.68 ; A V E_{S B}=.51 ; A V E_{A}=.48\right.$; $\left.A V E_{D}=.52 ; A V E_{B D}=.37\right)$.

Similarly, to the BriefCOPE at wave 1, the BriefCOPE at wave 2 had the loadings of each pair of items in each factor constrained to be equal. The CFA presented good fit $\left(\chi^{2}(234)=\right.$ $627.159, p<.001, N=360, \chi^{2} / d f=2.680, N F I=.977, C F I=.985, T L I=.979, S R M R=.072$, $R M S E A=.068, P($ rmsea $\leq .05)<.001,90 \% \mathrm{CI}] .062 ; .075[)$. The convergent validity evidence was satisfactory $\left(A V E_{A C}=.60 ; A V E_{P}=.65 ; A V E_{I S}=.77 ; A V E_{E S}=.74 ; A V E_{R}=.93 ; A V E_{P R}=.75\right.$; $\left.A V E_{S B}=.53 ; A V E_{A}=.63 ; A V E_{V}=.72 ; A V E_{D}=.59 ; A V E_{S D}=.43 ; A V E_{B D}=.76 ; A V E_{H}=.79\right)$.

Reliability of the scores. The UWES-S-9 presented good values of internal consistency estimates for the first-order factors: $\omega_{\text {Vigor }}=.81, \omega_{\text {Dedication }}=.81, \omega_{\text {Absorption }}=.88$. Regarding the internal consistency estimates of the second-order factor, the values were also good: $\omega_{L 1}=.91$, $\omega_{L 2}=.96, \omega_{\text {partial } L 1}=.95$. For the UWES-9 the values were good, both for the first-order factors 
$\left(\omega_{\text {Vigor }}=.92, \omega_{\text {Dedication }}=.90, \omega_{\text {Absorption }}=.74\right)$ as for the second-order factor $\mathrm{s}\left(\omega_{L 1}=.91, \omega_{L 2}\right.$

$\left.=.97, \omega_{\text {partial } L 1}=.94\right)$. At wave 1 the BriefCOPE first-order factors presented acceptable values $\left(\omega_{A C}=.84 ; \omega_{E S}=.55 ; \omega_{R}=.68 ; \omega_{P R}=.72 ; \omega_{S B}=.61 ; \omega_{A}=.56 ; \omega_{D}=.62 ; \omega_{B D}=.48\right)$. Overall, the BriefCOPE had good internal consistency values at wave $2\left(\omega_{A C}=.68 ; \omega_{P}=.72 ; \omega_{I S}=.79 ; \omega_{E S}\right.$ $\left.=.73 ; \omega_{R}=.90 ; \omega_{P R}=.79 ; \omega_{S B}=.59 ; \omega_{A}=.71 ; \omega_{V}=73 ; \omega_{D}=.65 ; \omega_{S D}=.51 ; \omega_{B D}=.74 ; \omega_{H}=.77\right)$.

\section{Structural Models}

Regarding the formulated hypotheses testing, the measurement model to test $\mathrm{H} 1$, revealed an acceptable fit $\left(\chi^{2}(297)=1,188.684, p<.001, \chi^{2} / d f=4.002, N=360, N F I=.974, C F I=.980\right.$, $T L I=.977$, SRMR $=.084$, RMSEA $=.091, P($ rmsea $\leq .05)<.001,90 \% \mathrm{CI}] .086 ; .097[)$. None of the predictors had a meaningful effect in work engagement, nevertheless the model explained $34.9 \%$ of the work engagement variance $\left(r^{2}\right.$ work engagement $\left.=.349\right)$. Table 2 presents the standardized factor weights $(\beta)$ and their $95 \%$ confidence intervals.

Table 2 about here

The measurement model of the latent factors to test $\mathrm{H} 2$, revealed a good fit $\left(\chi^{2}(545)=\right.$ $1,734.162, p<.001, \chi^{2} / d f=3.182, N=360, N F I=.971, C F I=.980, T L I=.975, S R M R=.084$, $R M S E A=.078, P($ rmsea $\leq .05)<.001,90 \%$ CI $] .074 ; .082[)$ explaining $21.9 \%$ of the work engagement variance $\left(r^{2}\right.$ work engagement $\left.=.219\right)$. Only self-blame had a meaningful effect in work engagement. Table 3 presents the standardized factor weights $(\beta)$ and their $95 \%$ confidence intervals.

\section{Table 3 about here}

In order to test the proposed cross-lagged model, and considering that the sample size was small regarding the number of parameters to be estimated in the cross-lagged model with the WLSMV estimator, the MLR estimator was used. The full cross-lagged model of the latent 
factors $(\mathrm{H} 3)$ revealed an acceptable fit $\left(\chi^{2}(1,659)=2,925.881, p<.001, \chi^{2} / d f=1.764, N F I=\right.$

$.785, C F I=.891, T L I=.867, S R M R=.057, R M S E A=.046, P($ rmsea $\leq .05)=.992,90 \% \mathrm{CI}$

].043; .049[). The explained variance ranges from low to moderate levels $\left(r^{2}\right.$ work engagement $=.250$;

$r_{A C}^{2}=.222 ; r_{P}^{2}=.032 ; r_{I S}^{2}=.210 ; r_{E S}^{2}=.284 ; r_{R}^{2}=.393 ; r_{P R}^{2}=.040 ; r_{S B}^{2}=.115 ; r_{A}^{2}=.075 ; r_{V}^{2}$

$\left.=.289 ; r_{D}^{2}=.156 ; r_{A}^{2}=.075 ; r_{S D}^{2}=.265 ; r_{B D}^{2}=.100 ; r_{H}^{2}=.166 ; r_{\text {Stress Appraisal }}^{2}=.247\right)$. The path between active coping at wave 1 predicted religion at wave 2 , and positive reframing at wave 1

predicted the same variable at wave 2 . Table 4 shows $\beta$ s and their correspondent $95 \%$ confidence intervals. Additionally data is included in Appendix 1 for reproducibility proposes.

Table 4 about here

\section{Discussion}

The aim of the present study was to investigate the relationship between stress appraisal, coping and engagement among police recruits undergoing academy training and one year after while working as officers. Findings suggest that individual processes such as coping or stress appraisal do not seem to be strong predictors of work engagement among recruits undergoing academy training and police officers working on duty. With the exception of self-blame that has shown to be a strong predictor of work engagement among police officers. In regards to the study hypotheses, H1 suggested that stress appraisal and coping would predict work engagement among police recruits; however findings did not confirm this prediction. Although the literature suggests that important drivers of engagement are both related with personal and job resources (Bakker et al., 2011), our findings suggest that personal resources particularly related to the way recruits appraise stress and cope do not seem to influence engagement. It is important 
to consider that these findings may be related with fact that police recruits in the current study perceived a reduced level of control over stressors $(M=2.42)$ experienced during academy training, what may consequently affect their coping strategies and respective link to engagement. Further research is warranted to confirm this assumption. Alternatively, these findings may suggest that other personal (e.g., personality) or job resources factors should be considered when aiming to predict work engagement among police recruits undergoing academy settings. In agreement with this assumption, previous research in an educational context (e.g., Alzyoud, Othman, \& Mohad Isa, 2015) found support that job resources are strong predictors of engagement levels. Similarly, emerging evidence (Akhtar, Boustani, Tsivrikos, \& Chamorro-Premuzic, 2015) in the work context supports the link between personality and work engagement. Hence, it is recommended that future research aiming to understand work engagement among police recruits considers the role of personality and job resources. Another possible explanation for the findings is the lack of sensitivity of the BriefCOPE scale to assess coping among student population (e.g., Lee \& Liu, 2001). Accordingly Carver (1997) recommended that researchers should use the BriefCOPE flexibly and creatively, such as by proposing the possibility of only selecting a sub-set of the sub-scales. This could be suggestive of the need to use a new version of the BriefCOPE adapted to educational contexts and students needs similarly to the UWES-S.

Regarding H2, it was hypothesized that stress appraisal and coping would predict engagement among police officers. Results only partially supported this hypothesis, as only statistically significant paths were found between self-blame and engagement. Self-blame can be classified as a form of EF coping indicating an inclination to respond to stressful situations, by criticizing or blaming oneself. This EF coping may decrease stress in the short term, but does not result in situational change (O’Neill \& Kerig, 2000). However, it is important to reinforce that by using self-blame as a coping strategy, this mean that officers are actually involved in the situations, to a point of blaming themselves for the problems encountered. Accordingly, evidence suggests that, this coping strategy is ineffective for police professional as it does not actively solve the problems, (Anshel et al., 2013). It is believe that these findings may be related with the nature of the police organization. This is a quasi-military structure with 
formal rules, rigid authority, resistance, and an authoritarian chain of command (Terpstra \& Schaap, 2013). Hence, police officers that perceive low perceptions of control over organizational decisions tend to use more EF coping (Lazarus \& Folkman, 1984). Further research is warranted to confirm this assumptions among police personnel, particularly controlling for perceptions of control over organizational decisions.

In what concerns to $\mathrm{H} 3$, it was predicted that stress appraisal, coping and engagement among recruits would predict stress appraisal, coping and engagement among police officers. Results fail to support this hypothesis, as no statistically significant path was found between a specific coping strategy, or stress appraisal and work engagement. It is important to note that the policing academy context and demands are completely different from those required for police officers on duty. Therefore, a recruit that may cope well with stress in an academy setting, might find it difficult to cope similarly with the professional demands. Similarly, as seen, the recruits coping experiences might be ineffective predicting work engagement, whereas there can be coping dimensions as police officers that can predict work engagement. Accordingly, Colwell et al. (2011) and Williams et al. (2010) suggested that officers face vastly different stress experiences over the course of their careers and particularly in the transition phase from being a recruit to officer. According to the authors, this transition comprises a complex process, associated with changes at both individual and work level. In support of this argument Li, Cheung and Sun (2018) have found that external factors such as job and family variables are important predictors of engagement levels among Asian police officers. Considering these findings further longitudinal research is required to explore the transition from recruits to officers and implications for work engagement.

\section{Limitations and future research avenues}

There are limitations in the present study that need to be acknowledged. First, results are primarily applied to the current sample, restricting generalizability to police forces from different countries. In addition, although the sample size (considering the difficult access to this population) is 
large, from a statistical perspective was not large enough to test $\mathrm{H} 3$ with the desired estimator (i.e., WLSMV).

Second, the instrument used to assess coping strategies (BriefCOPE) in police recruits show some limitations. Namely, low reliability estimates in some of its factors, although it might be due to the low number of indicators (i.e., two per factor). Hence, considering the complexity and the dynamic nature of stress and coping process, future research is warranted investigating these variables using complementary longitudinal research methods (e.g., daily diaries), attempting to reduce retrospective bias. Third, although stressors reported were related with work demands experienced, their typology was not defined in the current study. Hence, future qualitative research is encouraged to understand stress typology and respective appraisal among police recruits transitioning to officers. Considering the limited use of qualitative research designs in this area of study (e.g., Larsson, Berglund, \& Ohlsson, 2016) and their pertinence when aiming to understand stress and coping among police officers (e.g., Rodrigues, Kaiseler, Queirós, \& Basto-Pereira, 2017) we recommend a plea for more qualitative research. Finally, this study highlight the need to consider wider personal (e.g., personality; social support) and job resources (e.g., autonomy, role clarity, supervisor support) variables when aiming to fully understand the predictors of engagement among recruits and officers.

\section{Implications for practice}

Current findings suggest that internal processes such as stress appraisal and coping do not seem to be strong predictors of work engagement among recruits and police officers. Policy makers and practitioners aiming to increase work engagement among police recruits and officers should therefore consider wider personal (e.g., social support and personality) and job resources variables (e.g., (e.g., autonomy, role clarity, supervisor support). Considering the compelling body of research investigating

It is worth reflecting that stress has been a common problem over the years in police organizations, which makes us think that this problem should not only be addressed at a micro level, that is focusing mainly on the individual, but also at a macro level, that is the organization (Shane, 2013). The 
organization has shown to have a crucial role in enhancing officers' engagement as proposed by Gillet, Huart, Colombat, and Fouquereau (2013). The authors suggested that police professionals who feel that they are supported by their organization (e.g., recognition, approval, appreciation of work) show higher levels of work engagement. Based on the assumption that engaged workers are less susceptible to experience stress (Bakker, 2009), police practitioners, and officers themselves should focus on enhancing both personal and job resources in order to increase engagement levels, starting in the academy period.

Acknowledging the importance of personal and job resources on police officers engagement, it is recommended that future intervention in this area are holistic in nature, comprising both organizational as well as health promotion elements. Accordingly, recent evidence from a systematic review of health promotion intervention studies among police officers conducted by Kolt et al. 2017 reinforces the importance of education and behavior change interventions among this population.

In conclusion the present study found that police recruits coping strategies have very limited impact in engagement levels during the academy period. Hence, future research should consider the importance of job resources when promoting engagement in this setting. Additionally, it seems that EF coping (i.e. self-blame) predicts engagement levels among police officers. Given that emerging evidence suggesting that high engagement levels may have a positive influence on health, well-being and work-related attitudes, more attention should be dedicated to ways of developing engagement levels throughout the policing career. 


\section{References}

Akhtar, R., Boustani, L., Tsivrikos, D., \& Chamorro-Premuzic, T. (2015). The engageable personality: Personality and trait EI as predictors of work engagement. Personality and Individual Differences, 73, 44-49. doi:10.1016/j.paid.2014.08.040

Alexander, D., \& Walker, L. (1994). A study of methods used by Scottish police officers to cope with work-induced stress. Stress Medicine, 10, 131-138.

Alzyoud, A. A. Y., Othman, S. Z., \& Mohad Isa, M. F. (2015). Examining the role of job resources on work engagement in the academic setting. Asian Social Science, 11(3), 103110. doi:10.5539/ass.v11n3p103

Anshel, M.H., Umscheid, D., \& Brinthaupt, T.M. (2013). Effect of a combined coping skills and wellness program on perceived stress and physical energy among police emergency dispatchers: An exploratory study. Journal of Police and Criminal Psychology, 28, 1-14. doi:10.1007/s11896-0129110-x

Bakker, A.B. (2009). Building engagement in the workplace. In R. J. Burke \& C.L. Cooper (Eds.),The peak performing organization (pp. 50-72). Oxon, UK: Routledge.

Bakker, A.B., Albrecht, S.L., \& Leiter, M.L. (2011). Key questions regarding work engagement. European Journal of Work and Organizational Psychology, 20(1), 4-28. doi:10.1080/1359432X.2010.485352

Bakker, A.B, \& Leiter, M. (2010). Work Engagement: A Handbook of Essential Theory and Research. East Sussex: Psychology Press.

Bakker, A.B., Schaufeli, W.B., Leiter, M.P., \& Taris, T.W. (2008). Work engagement: An emerging concept in occupational health psychology. Work \& Stress, 22, 187-200.

Bollen, K. A. (1980). Issues in the comparative measurement of political democracy. American Sociological Review, 45(3), 370-380. https://doi.org/10.2307/2095172Boomsma, A. (2000). 
Reporting analyses of covariance structures. Structural Equation Modeling: A Multidisciplinary Journal, 7(3), 461-483. https://doi.org/10.1207/S15328007SEM07036

Breevaart, K., Bakker, A.B., Demerouti, E., \& van den Heuvel, M. (2015). Leader-member exchange, work engagement, and job performance. Journal of Managerial Psychology, 30(7), 1-33.

doi:10.1108/JMP-03-2013-0088

Byrne, B. M. (2010). Structural Equation Modeling with AMOS (3rd ed.). New York, NY, USA: Routledge. https://doi.org/10.4324/9781410600219

Carver, C. S. (1997). You want to measure coping but your protocol's too long: Consider the Brief COPE. International Journal of Behavioral Medicine, 4, 92-100.

Carver, C.S., Scheier, M.F., \& Weintraub, J.K. (1989). Assessing coping strategies: a theoretical-based approach. Journal of Personality and Social Psychology, 56, 375-390.

Chappell, A. T., \& Lanza-Kaduce, L. (2010). Police academy socialization: understanding the lessons learned in a paramilitary-bureaucratic organization. Journal of Contemporary Ethnography, 39(2), 187-214. doi:10.1177/0891241609342230

Colwell, L.H., Lyons, P.M., Bruce, A.J., Garner, R.L., \& Miller, R.S. (2011). Police officers' cognitive appraisals for traumatic events: implications for treatment and training. Applied Psychology in Criminal Justice, 7(2), 106-132.

Finney, S. J., \& DiStefano, C. (2013). Non-normal and categorical data in structural equation modeling. In G. R. Hancock \& R. O. Mueller (Eds.), Structural equation modeling: A second course (2nd ed., pp. 439-492). Charlotte, NC, USA: Information Age Publishing.

Finney, S. J., DiStefano, C., \& Kopp, J. P. (2016). Overview of estimation methods and preconditions for their application with structural equation modeling. In K. Schweizer \& C. DiStefano (Eds.), Principles and methods of test construction: Standards and recent advances (pp. 135-165). Boston, MA, USA: Hogrefe Publishing. https://doi.org/10.1027/00449-000

Folkman, S., \& Moskowitz, J. T. (2004). Coping: pitfalls and promise. Annual Review of Psychology, 55, 745-74. doi:10.1146/annurev.psych.55.090902.141456 
Fornell, C., \& Larcker, D. F. (1981). Evaluating structural equation models with unobservable variables and measurement error. Journal of Marketing Research, 18, 39-50. https://doi.org/10.2307/3151312

Gillet, N., Huart, I., Colombat, P., \& Fouquereau, E. (2013). Perceived organizational support, motivation, and engagement among police officers. Professional Psychology: Research and Practice, 44(1), 46-55. doi:10.1037/a0030066

Hair, J. F., Black, W. C., Babin, B. J., \& Anderson, R. E. (2009). Multivariate data analysis (7th ed.). Upper Saddle River, NJ, USA: Prentice Hall.

Hoyle, R. H. (Ed.). (1995). Structural equation modeling: Concepts, issues and applications. Thousand Oaks, CA, USA: SAGE Publications.

Hickman, M.J., Fricas, J., Strom, K.J., \& Pope, M.W. (2011). Mapping police stress. Police Quarterly, 14(3), 227-250. doi:10.1177/1098611111413991

Kaiseler, M., Queirós, C., Passos, F., \& Sousa, P. (2014). Stress appraisal, coping, and work engagement among police recruits: an exploratory study. Psychological Reports: Employment Psychology \& Marketing, 114(2), 1-12. doi:10.2466/01.16.PR0.114k21w2

Kolt, G., MacMillan, F., Karamacoska, D., El Masri, A., McBride, K., Steiner, G., Cook, A., Klupp, N., \& George, E. (2017). A systematic review of health promotion intervention studies in the police force. Journal of Science and Medicine in Sport, 20(3), 20-33. doi:10.1016/j.jsams.2017.09.234

Larsson, G., Berglund, A.K., \& Ohlsson, A. (2016). Daily hassles, their antecedents and outcomes among professional first responders: A systematic literature review. Scandinavian Journal of Psychology, 57, 359-367. doi:10.1111/sjop.12303

Lazarus, R. S., \& Folkman, S. (1984). Stress, coping and adaptation. New York: Springer.

Lee, R.M., \& Liu, H.T.T. (2001). Coping with intergenerational family conflict: Comparison of Asian American, Hispanic, and European American college students. Journal of Counseling Psychology, 48, 410-419. doi:10J037//0022-0167.48.4.410 
Lemon, J. (2006). Plotrix: a package in the red light district of R. $R$-News, 6(4), 8-12. Retrieved from https://www.r-project.org/doc/Rnews/Rnews_2006-4.pdf

Li, J.C.M., Cheung, J.C.K., \& Sun, I.Y. (2018). The impact of job and family factors on work stress and engagement among Hong Kong police officers. Policing: An International Journal. doi:1108/PIJPSM-01-2018-0015

Lüdecke, D. (2019). sjstats: Statistical functions for regression models (R package version 0.17.3) [Computer software]. https://doi.org/10.5281/zenodo.1284472

Marôco, J. (2014). Análise de equações estruturais: Fundamentos teóricos, software \& aplicações Pêro Pinheiro, Portugal: ReportNumber.

McCarty, W.P., \& Lawrence, D.S. (2016). Coping, confidence, and change within the academy: a longitudinal look at police recruits. Police Practice and Research, 17(3), 263-278. doi:10.1080/15614263.2014.958486

McDonald, R. P., \& Ho, M.-H. R. (2002). Principles and practice in reporting structural equation analyses. Psychological Methods, 7(1), 64-82. https://doi.org/10.1037/1082-989X.7.1.64

McNamara, A., Arino de la Rubia, E., Zhu, H., Ellis, S., \& Quinn, M. (2018). skimr: Compact and flexible summaries of data ( $\mathrm{R}$ package version 1.0.3) [Computer software]. Retrieved from https://cran.rproject.org/package $=$ skimr

Muthén, B. O. (1983). Latent variable structural equation modeling with categorical data. Journal of Econometrics, 22(1-2), 43-65. https://doi.org/10.1016/0304-4076(83)90093-3

O’Neill, M. \& Kerig, P. (2000). Attributions of self-blame and perceived control as moderators of adjustment in batterered women. Journal of Interpersonal Violence, 15(10), 1036- 1049.

Ouweneel, E., Le Blanc, P.M., Schaufeli, W.B. \& van Wijhe, C.I. (2012). Good morning, good day: A diary study on positive emotions, hope, and work engagement. Human Relations, 65(9), 1129-1154. doi:10.1177/0018726711429382 
Pais Ribeiro, J.L., \& Rodrigues, A.P. (2004). Questões acerca do coping: a propósito do estudo de adaptação do briefCOPE. Psicologia, Saúde \& Doenças, 5(1), 3-15.

Picado, L., Marques Pinto, A., \& Lopes da Silva, A. (2008). O papel dos esquemas precoces mal adaptativos na relação entre a ansiedade e o burnout / engagement dos professores portugueses do $1^{\circ}$ ciclo. In A. Marques Pinto \& M. J. Chambel (Eds.), Burnout e engagement em contexto organizacional. Estudos com amostras portuguesas (pp. 167-198). Lisboa: Livros Horizonte.

R Core Team. (2018). R: A language and environment for statistical computing (version 3.5.1) [Computer software]. Vienna, Austria: R Foundation for Statistical Computing. Retrieved from https://www.rproject.org/

Raykov, T. (2001). Estimation of congeneric scale reliability using covariance structure analysis with nonlinear constraints. The British Journal of Mathematical and Statistical Psychology, 54, 315-323. https://doi.org/10.1348/000711001159582

Revelle, W. (2018). psych: Procedures for psychological, psychometric, and personality research (R package version 1.8.12) [Computer software]. Evanston, IL: Northwestern University. Retrieved from https://cran.r-project.org/package=psych

Rosseel, Y. (2012). lavaan: An R package for structural equation modeling. Journal of Statistical Software, 48(2), 1-21. https://doi.org/10.18637/jss.v048.i02

Rothmann, S., Jorgensen, L.I., \& Hill, C. (2011). Coping and work engagement in selected South African organizations. SA Journal of Industrial Psychology, 7(1), 1-11. doi:10.4102/sajip.v37i1.962

Rodrigues, S., Kaiseler, M., Queirós, C., \& Basto-Pereira, M. (2017). Daily stress and coping among emergency response officers: a case study. International Journal of Emergency Services, 6(2), 122133. doi:10.1108/IJES-10-2016-0019

RStudio Team. (2018). RStudio: Integrated development for R (version 1.1.463) [Computer software]. Boston, MA, USA: RStudio, Inc. Retrieved from http://www.rstudio.com/ Sakakibara, R., \& Endo, T. (2016). Cognitive appraisal as a predictor of cognitive emotion regulation choice. Japanese Psychological Research, 58(2), 175-185. doi:10.1111/jpr.12098 
Sced, M., \& Baur, J. (2007). Burnout and engagement in police recruits: A typology. Australasian Council for Policing Research, 2, 1-12.

Schaufeli, W.B., \& Bakker, A.B. (2004). Job demands, job resources and their relationship with burnout and engagement: A multi-sample study. Journal of Organizational Behavior, 25, 293-315.

Schaufeli, W.B., \& Bakker, A.B. (2009). Escala de engagement no trabalho de Utrecht [Utrech Engagement Scale]. (A. M. T. Benevides-Pereira \& P. C. Porto-Martins, Trans.). Utrecht: Utrecht University.

Schaufeli, W.B., Bakker, A.B., \& Salanova, M. (2006). The measurement of work engagement with a brief questionnaire: A cross-national study. Educational and Psychological Measurement, 66, 701716.

Schaufeli, W B., Salanova, M., González-Romá, V., \& Bakker, A.B. (2002). The measurement of engagement and burnout and: A confirmative analytic approach. Journal of Happiness Studies, 3, 7192.

Schiffrin, H.H., \& Nelson, S.K. (2009). Stressed and happy: Investigating the relationship between happiness and perceived stress. Journal of Happiness Studies, 11, 22-39. doi:10.1007/s10902-0089104-7

Seligman, M. E. P., \& Csikszentmihalyi, M. (2000). Positive psychology: An introduction. American Psychologist, 55, 5-14. doi:10.1037/0003-066X.56.1.89

Shane, J. M. (2013). Daily work experiences and police performance. Police Practice and Research, 14(1), 17-34. doi:10.1080/15614263.2011.596717

Sinval, J., Marques-Pinto, A., Queirós, C., \& Marôco, J. (2018). Work engagement among rescue workers: Psychometric properties of the Portuguese UWES. Frontiers in Psychology, 8. https://doi.org/10.3389/fpsyg.2017.02229 
Sinval, J., Pasian, S. R., Queirós, C., \& Marôco, J. (2018). Brazil-Portugal transcultural adaptation of the UWES-9: Internal consistency, dimensionality, and measurement invariance. Frontiers in Psychology, 9, 1-18. https://doi.org/10.3389/fpsyg.2018.0035

Sonnentag, S., Dormann, C., \& Demerouti, E. (2010). Not all days are created equal: The concept of state work engagement. In A.B. Bakker \& M.P. Leiter (Eds.), Work Engagement: A Handbook of Essential Theory and Research (pp. 25-38). New York: Psychology Press.

Stepka, E., \& Basinska, M.A. (2014). Chronic fatigue and strategies of coping with occupational stress in police officers. Medycyna Pracy, 65(2), 229-238. doi:10.13075/mp.5893.2014.033

Strahler, J., \& Ziegert, T. (2015). Psychobiological stress response to a simulated school shooting in police officers. Psychoneuroendocrinology, 51, 80-91. doi:10.1016/j.psyneuen.2014.09.016

Super, D.E. (1990). A life span, life-space approach to career development. In D. Brown, \& L. Brooks (Eds.), Career choice and development (2nd ed.). San Francisco: Jossey-Bass.

Terpstra, J., \& Schaap, D. (2013). Police culture, stress conditions and working styles. European Journal of Criminology, 10(1) 59-73. doi:10.1177/1477370812456343

Westland, J.C. (2010). Lower bounds on sample size in structural equation modeling. Electronic Commerce Research and Applications, 9(6), 476-487.

Williams, V. Ciarrochi, J., \& Deane, F. P. (2010). On being mindful, emotionally aware, and more resilient: Longitudinal pilot study of police recruits. Australian Psychologist, 45(4), 274-282. doi:10.1080/00050060903573197

Young, P. M., Partington, P., Wetherell, M. A., Gibson, A. C., \& Partington, E. (2014). Stressors and coping strategies of UK firefighters during on-duty incidents [Special issue]. Stress and Health. doi:10.1002/smi.2616

Zakowski, S.G., Hall, M.H., Klein, L.C., \& Baum, A. (2001). Appraised control, coping, and stress in a community sample: a test of the goodness-of-fit hypothesis. Annals of Behavior Medicine, 23, 158165 